\title{
Pharmacokinetics of chemotherapeutic agents in pregnancy: a preclinical and clinical study
}

\begin{abstract}
KRISTEL VAN CALSTEREN ${ }^{1}$, RENÉ VERBESSELT ${ }^{2}$, NELLEKE OTTEVANGER ${ }^{3}$, MICHAEL HALASKA ${ }^{4}$, LIESBETH HEYNS ${ }^{1}$, RIETA VAN BREE ${ }^{1}$, ERNST DE BRUIJN $^{5}$, DANIEL CHAI ${ }^{6}$, MICHEL DELFORGE $^{7}$, LUCIEN NOENS $^{8}$, VINCENT RENARD ${ }^{9}$, ELS WITTEVEEN ${ }^{10}$, LUKAS ROB ${ }^{4}$, JAN DE HOON ${ }^{2}$ \& FRÉDÉRIC AMANT ${ }^{1}$
\end{abstract}

\begin{abstract}
${ }^{1}$ Department of Obstetrics \& Gynecology, Division of Gynecological Oncology, University Hospital Gasthuisberg, Katholieke Universiteit Leuven, Leuven, Belgium, ${ }^{2}$ Center for Clinical Pharmacology, University Hospital Gasthuisberg, Katholieke Universiteit Leuven, Leuven, Belgium, ${ }^{3}$ Department of Medical Oncology, Radboud University Nijmegen Medical Centre, Nijmegen, The Netherlands, ${ }^{4}$ Department of Obstetrics E Gynecology, Division of Gynecology Oncology, Charles University in Prague, 2nd Medical Faculty, Czech Republic, ${ }^{5}$ Laboratory of Medical Oncology, University Hospital Gasthuisberg, Katholieke Universiteit Leuven, Leuven, Belgium, ${ }^{6}$ Department of Reproductive Biology, Institute of Primate Research, Nairobi, Kenya, ${ }^{7}$ Department of Hematology, University Hospital Gasthuisberg, Katholieke Universiteit Leuven, Belgium, ${ }^{8}$ Department of Hematology, University Hospital Gent, Gent, Belgium, ${ }^{9}$ Deparment of Radiotherapy, Oncology and Hematology, AZ Sint-Lucas, Gent, Belgium, and ${ }^{10}$ Department of Medical Oncology, University Medical Center Utrecht, The Netherlands
\end{abstract}

\begin{abstract}
Objective. To determine the impact of physiologic changes of pregnancy on pharmacokinetics of chemotherapeutic agents. Design. A preclinical and a clinical case-control trial. Setting. Institute of Primate Research Nairobi and collaborating hospitals in Belgium, the Netherlands and Czech Republic. Population. Pregnant and nonpregnant women and baboons receiving chemotherapy. Methods. Chemotherapy pharmacokinetics was compared between the pregnant and nonpregnant state. Standard-dosed chemotherapy regimens were administered in pregnant and nonpregnant baboons/women, followed by serial blood samplings. Drug plasma levels were determined using high performance liquid chromatography and atomic absorption spectrometry. Main outcome measures. Area under the curve (AUC), maximal plasma concentration, terminal elimination half-life, clearance and distribution volume of each drug in pregnant and nonpregnant state. Results. Intraindividual comparative pharmacokinetic data were obtained for doxorubicin and paclitaxel/platinum in three and two baboons, respectively. In the clinical trial, two patients were exposed to doxorubicin and one patient was exposed to paclitaxel/ platinum during and after pregnancy. Furthermore, a pooled analysis was performed based on 16 cycles of pregnant and 11 cycles of nonpregnant women. Numbers of pregnant/nonpregnant patients were 5/2, 7/5, 4/4 and 2/2 for paclitaxel, doxorubicin, epirubicin and platinum, respectively. For all drugs tested in the preclinical and clinical study, a decreased AUC and maximal plasma concentration and an increased distribution volume and clearance were observed in pregnancy. Conclusions. Although numbers were too small for statistical significance, pregnancy-associated physiologic alterations appear to lead to a decrease in plasma exposure of chemotherapeutic drugs. The importance of long-term follow-up of women treated with chemotherapy during pregnancy is underscored.
\end{abstract}

Key words: Chemotherapy, pharmacokinetics, pregnancy, baboon

Correspondence: Frédéric Amant, Leuven Cancer Institute (LKI), Department of Obstetrics \& Gynecology, Division of Gynecological Oncology, University Hospital Gasthuisberg, Katholieke Universiteit Leuven, Herestraat 49, 3000 Leuven, Belgium. E-mail: Frederic.amant@uz.kuleuven.ac.be 


\section{Introduction}

Most anticancer drugs exhibit a narrow therapeutic window with small margins between toxic and therapeutic exposure. Interindividual pharmacokinetic and pharmacodynamic variability is usually substantial and may be augmented by pregnancy (1). During pregnancy multiple changes in physiology occur affecting the major pharmacokinetic processes including absorption, distribution, metabolism and excretion (2).

The distribution volume of drugs may be increased during pregnancy as a result of the increase in extracellular fluid volume and plasma volume expansion by $50 \%$. As pregnancy advances, the plasma volume expands at a higher rate than the increase in albumin production, creating a dilutional hypoalbuminemia, which might increase the fraction of unbound drugs (3). Increased secretion of estrogen and progesterone during normal pregnancy can induce or inhibit hepatic drug metabolism. This cholestatic effect of estrogen may interfere with biliary drug clearance. Increased renal blood flow and glomerular filtration during pregnancy may result in increased renal elimination (3).

In the absence of valid data, currently the same dosing regimens are administered in pregnant and nonpregnant women. However, due to the lack of prospective controlled studies exploring relations between dose-pharmacokinetics and pharmacodynamics during pregnancy it is unknown whether the pregnant patient is treated optimally with standard chemotherapy regimens as applied in current clinical practice to patients in the nonpregnant state $(4,5)$.

Therefore, we initiated a study examining pharmacokinetic parameters of cytotoxic drugs in pregnancy. Firstly, we designed a pregnant baboon model to test gestational effects on pharmacokinetics. Because of the close phylogenetic relation between humans and nonhuman primates, the reproductive physiology and endocrinology of pregnancy and drug metabolism are very similar, allowing extrapolation of data to the human setting (6).

Secondly, a clinical study was performed to compare pharmacokinetic parameters between the pregnant and nonpregnant state intra- and interindividually.

\section{Material and methods}

\section{Accrual and drugs in the baboon study}

The study protocol was approved by the Institutional Scientific and Ethical Review Committee of the Institute of Primate Research, Nairobi, Kenya. Animals were treated according to guidelines for Good Laboratory Practices.

This study was part of a project investigating the transplacental transfer and pharmacokinetics of chemotherapeutic agents in baboon model. In total 19 animals were used for the investigation of transplacental transfer of chemotherapy, in five of them a series of maternal blood samples also were collected over the first 24 hours after drug infusion for pharmacokinetic analysis. In these five baboons, an identical administration and sampling scheme was applied once more at least 40 days postpartum. This moment was chosen since hemodynamic changes are known to return to pre-pregnant baseline within 6 weeks following delivery.

After capturing the baboons (Papio anubis), physical examinations and infectious screenings were performed and 3 months of quarantine were completed. Animals were timed-mated based on daily recording of the changes in the perineal sex skin as previously described (7). The baboons were housed in single cages, except for the period of timed mating, and were fed on a daily diet of high protein pellets.

Combination regimens of chemotherapeutic drugs were administered under general anesthesia. Therefore, animals were sedated with an intramuscular injection of ketamine $10 \mathrm{mg} / \mathrm{kg}$ and xylazine $0.5 \mathrm{mg} / \mathrm{kg}$ and endotracheally intubated. General anesthesia was induced with halothane, nitrous oxide and oxygen. Chemotherapy was administered through a femoral vein catheter $(20 \mathrm{G})$. The contralateral femoral vein was catheterized for serial blood samplings. A urinary catheter $(10 \mathrm{Ch})$ was used for urine drainage. When chemotherapy administration was completed, the animals were placed in a restrain chair for 12 or 24 hours, allowing further blood samplings.

The tested drug regimens included a combination of doxorubicin $\left(25 \mathrm{mg} / \mathrm{m}^{2}\right)$, bleomycin $\left(10 \mathrm{mg} / \mathrm{m}^{2}\right)$, vinblastine $\left(6 \mathrm{mg} / \mathrm{m}^{2}\right)$ and dacarbazine $\left(375 \mathrm{mg} / \mathrm{m}^{2}\right)$ (ABVD) and a combination of paclitaxel $\left(175 \mathrm{mg} / \mathrm{m}^{2}\right)$ and carboplatin. For carboplatin, the dosage was determined according to the Calvert's formula $($ dose $=$ target area under the curve $(\mathrm{AUC}) \times($ glomerular filtration rate +25$)$ ) (8) with a target AUC of 6. Glomerular filtration rate was estimated based on the Schwartz formula $(0.55 \times$ height $(\mathrm{cm}) /$ serum creatinine $(\mathrm{mg} / \mathrm{dl}) \times$ (body surface area/1.73). Drug administration occurred in a similar way as in clinical practice, including premedication with alizapride, and for paclitaxel-including regimens also cetirizine, solumedrol and ranitidine were used.

Carboplatin (Carbosin ${ }^{\circledR}$ ), doxorubicin (Doxorubicin $^{\circledR}$ ), bleomycin $\left(\right.$ Bleomin ${ }^{\circledR}$ ), dacarbazin (Dacarbazine $\left.{ }^{\circledR}\right)$, vinblastine $\left(\right.$ Vinblastin $^{\circledR}$ ) and paclitaxel 
$\left(\right.$ Paxene ${ }^{\circledR}$ ) were kindly provided by Teva Pharma Belgium NV, Wilrijk, Belgium.

\section{Accrual and drugs in the clinical study}

Pregnant patients diagnosed with cancer necessitating chemotherapy were identified in an international collaborative setting. Postpartum and nonpregnant matched women constituted the control group.

The study was approved by the institutional review board in all participating centers, including University Hospital Gasthuisberg Leuven, University Hospital Gent, General Hospital Jan Palfijn Brugge, General Hospital St Jozef Turnhout in Belgium and Radboud University Medical Centre in Nijmegen, University Medical Center Utrecht and Catharina Hospital Eindhoven in The Netherlands and the Motol Hospital Prague in the Czech Republic.

Informed consent was obtained from all patients in accordance with institutional regulations.

Patients received standard regimens of combination chemotherapy as currently applied in the diseasespecific oncological treatment of nonpregnant women (ABVD: Doxorubicin, Bleomycin, Vinblastine, Dacarbazine; (F)AC: (5-Fluorouracil), Doxorubicin, Cyclophosphamide; FEC: 5-Fluorouracil, Epirubicin, Cyclophosphamide; (R-)CHOP: (Rituximab), Cyclophosphamide, Doxorubicin, Vincristine, Prednisolone; Paclitaxel +/- Carboplatin or Cisplatin). Dosage was body surface area-based for most drugs. Only carboplatinum dosage was determined based on the creatinine clearance, according to the Calvert's formula (8). Glomerular filtration rate was estimated based on the Cockroft formula: $((140-$ age $(\mathrm{y})) \times$ weight $(\mathrm{kg}) \times 0.85) /(72 \times$ serum creatinine $(\mathrm{mg} / \mathrm{dl}))(9)$.

\section{Blood sample collection}

From the start of the drug infusion, blood samples were collected over 24 hours in the baboon study and over 48 hours in the clinical study. For short infusions $\left(<90^{\prime}\right)$, the first sample was collected at the end of the infusion of interest. Subsequently target sampling times were 15 and 30 minutes and 1, 2, 4, 6, 8, 12,24 and 48 hours after the end of the drug infusion. For longer infusions $\left(>90^{\prime}\right)$, also during drug infusion, a blood sample was collected every hour. Whenever sampling times varied, this was noted. Variability was due to overlap when two drugs were tested in a combination scheme, and technical difficulties to withdraw blood.

Blood samples were collected in EDTA-tubes and centrifuged $\left(3,000 \mathrm{rpm}, 4^{\circ} \mathrm{C}, 10\right.$ minutes) within 2 hours. Plasma was stored at $-80^{\circ} \mathrm{C}$ until analysis.
Drug analysis

Levels of doxorubicin, epirubicin and paclitaxel were determined in plasma by high performance liquid chromatography. Total platinum was determined using atomic absorption spectrometry.

Doxorubicin and epirubicin were determined in plasma by high performance liquid chromatography. Drugs were extracted from plasma at $\mathrm{pH} 9.0$ with borate buffer and a chloroform-2-propanol mixture $(85 / 15, \mathrm{v} / \mathrm{v})$. Calibration curves were constructed in the blank plasma. Chromatographic analysis was carried out by reversed-phase isocratic elution on a high performance liquid chromatography column filled with Hypersil BDS $5 \mu(250 \times 4.6 \mathrm{~mm}$ I.D. $)$ with a mobile phase mixture of acetonitrile and potassium phosphate buffer $15 \mathrm{mM} \mathrm{pH} 3.0(+0.05 \%$ triethylamine) $(25 / 75, \mathrm{v} / \mathrm{v})$. For doxorubicin determination, epirubicin was used as internal standard. For epirubicin determination doxorubicin was used as internal standard.

Detection was accomplished by fluorometry with a Waters 2475 fluorescence detector at excitation and emission wavelengths of 480 and $560 \mathrm{~nm}$, respectively.

The method was linear over a concentration range of $2.5-1,000 \mathrm{ng} / \mathrm{ml}$ for doxorubicin and epirubicin.

The average recoveries of doxorubicin and epirubicin from plasma were $78.3 \pm 7.6 \%$ (mean \pm SD) and $79.0 \pm 12.1 \%$, respectively. The lower limit of quantification was $2.5 \mathrm{ng} / \mathrm{ml}$ and the method proved to be precise and accurate, as the intra- and interday coefficients of variation were less than $15 \%$.

Paclitaxel was determined in plasma by high performance liquid chromatography after plasma extraction with a mixture of hexane and ethylacetate $(50 / 50$, $\mathrm{v} / \mathrm{v})$, buffered with ammoniumacetate $0.1 \mathrm{M} \mathrm{pH} 5$. For paclitaxel determination docetaxel was used as internal standard. Calibration curves were constructed in the blank plasma.

Separation of paclitaxel was performed on a reversed-phase column packed with Novapack C8 $4 \mu$, using a mobile phase mixture of acetonitrile and $20 \mathrm{mM}$ ammoniumacetate buffer $\mathrm{pH} 5$ (40/60, $\mathrm{v} / \mathrm{v}$ ) at a flow rate of $1 \mathrm{ml} /$ minute and UV detection at $227 \mathrm{~nm}$.

Linearity of the calibration curves for paclitaxel was found in the range of $25-5,000 \mathrm{ng} / \mathrm{ml}$. The lower limit of quantification for paclitaxel was $25 \mathrm{ng} / \mathrm{ml}$, being the lowest concentration of the standard curve with a coefficient of variation lower than $20 \%$. Analytical recovery (\%) of paclitaxel from plasma was $101.0 \pm$ 11.7 (mean $\pm \mathrm{SD}$ ). Coefficients of variation for intraand interday precision and accuracy were all below $15 \%$. 
For the determination of total platinum, plasma samples were diluted six times in water and $20 \mu 1$ of the solution was injected in the atomic absorption spectrometer with pyrocoated graphite tube and cathode Pt-lamp (Zeeman/3030, Perkin-Elmer, Shelton, USA). Quantification was performed with a calibration curve (matrix matched), which was linear over the range $178-1,048 \mu \mathrm{g} / \mathrm{L}$ with a coefficient of variation of $6.2 \%$. The detection limit was $10 \mu \mathrm{g} / \mathrm{L}$.

\section{Pharmacokinetic data analysis}

Pharmacokinetic analysis was performed using WinNonLin (Pharsight, Mountain View, CA) with the non-compartmental, linear up log down application. $\mathrm{C}_{\max }$ indicates the maximal plasma concentration. Terminal elimination half-life $\left(t_{1 / 2}\right)$ was calculated from the slope $(\lambda)$ of the linear regression analysis over the (semi-logarithmic) last four plasma concentration versus time points: $t_{1 / 2}=\ln 2 / \lambda$. AUC was calculated by the trapezoidal method with extrapolation to infinity. Total body clearance $(\mathrm{Cl})$ was calculated by the formula: $\mathrm{Cl}=$ Dose/AUC; and distribution volume $\left(\mathrm{V}_{\mathrm{d}}\right)$ by: $\mathrm{V}_{\mathrm{d}}=\mathrm{Cl} / \lambda$.

For the comparison of results, $\mathrm{C}_{\max }$ and AUC were corrected for dose and infusion time $\left(\mathrm{C}_{\max }-\mathrm{D} \times \mathrm{IT}\right)$ and for dose (AUC - D), respectively.

\section{Statistics}

Data are shown in mean + SD. Because of the small number of baboons, no statistical analysis was performed on the preclinical data. For the clinical study, statistical testing was performed with Graphpad Prism 5 (GraphPad Software, Inc., La Jolla, CA, USA). Given the small numbers, a non-parametric two-sided Wilcoxon rank-sum test was applied to compare continuous variables in two groups. Results were considered significant at $p<0.05$.

\section{Results}

Baboon study

Five baboons received an identical regimen of chemotherapy once during pregnancy (mean gestational age $142+9$ days) and once during postpartum $(56+$ 11 days postpartum). The mean height of the animals was $95.6+1.4 \mathrm{~cm}$, the mean weight during pregnancy was $16.1+1.0 \mathrm{~kg}$ and the weight postpartum was $14.3+1.5 \mathrm{~kg}$.

Three baboons received doxorubicin, two baboons were exposed to the combination of paclitaxel and carboplatin (Table 1).

Table 2 shows the pharmacokinetic parameters of doxorubicin obtained in pregnant and postpartum baboons. Comparison of the results revealed a similar pattern in the three tested animals. $\mathrm{C}_{\max }-\mathrm{D}$ was remarkably lower during pregnancy (39\% reduction), as well as AUC - D and $\mathrm{t}_{1 / 2}$ (42 and $32 \%$ reduction, respectively). Drug clearance was $77 \%$ higher during pregnancy. Compared to postpartum values, an $18 \%$ increase in distribution volume was noted during pregnancy (Table 2).

In Table 3, the pharmacokinetic parameters for paclitaxel and platinum are presented. In PAN2656, no blood sample was available exactly at the end of the platinum infusion. As a result $\mathrm{C}_{\max }$ and AUC could not be determined. The results between both animals varied substantially. However, both revealed a lower $\mathrm{C}_{\max }-\mathrm{D}$, a lower AUC $-\mathrm{D}$, and an increased clearance, $\mathrm{t}_{1 / 2}$ and distribution volume during pregnancy (Table 3).

\section{Clinical study}

In total 16 cycles from pregnant patients were available and 11 from nonpregnant women (4 postpartum, 7 not related to pregnancy). Patient characteristics

Table 1. Overview of baboon characteristics and drug infusion schemes.

\begin{tabular}{|c|c|c|c|c|c|c|c|c|c|}
\hline \multirow[b]{2}{*}{ Baboon } & \multirow[b]{2}{*}{ Drug } & \multicolumn{2}{|c|}{$\begin{array}{l}\text { Gestational } \\
\text { state (days) }\end{array}$} & \multicolumn{2}{|c|}{ BSA } & \multicolumn{2}{|c|}{ Dose (mg) } & \multicolumn{2}{|c|}{ IT (hour) } \\
\hline & & GA & $\mathrm{PP}$ & GA & PP & $\operatorname{Pr}$ & PP & $\operatorname{Pr}$ & PP \\
\hline$\overline{\text { PAN2044 }}$ & Doxorubicin $25 \mathrm{mg} / \mathrm{m}^{2 \mathrm{a}}$ & 157 & 40 & 0.64 & 0.58 & 15.5 & 14.5 & 0.3 & 0.3 \\
\hline PAN2596 & Doxorubicin $25 \mathrm{mg} / \mathrm{m}^{2 \mathrm{a}}$ & 146 & 57 & 0.67 & 0.60 & 16.6 & 15.0 & 0.3 & 0.4 \\
\hline PAN3072 & Doxorubicin $25 \mathrm{mg} / \mathrm{m}^{2 \mathrm{a}}$ & 137 & 67 & 0.61 & 0.60 & 15.2 & 15.0 & 0.3 & 0.3 \\
\hline \multirow[t]{2}{*}{ PAN2656 } & Paclitaxel $175 \mathrm{mg} / \mathrm{m}^{2}$ & 139 & 65 & 0.66 & 0.64 & 115.0 & 112.0 & 3.0 & 3.0 \\
\hline & Carboplatin AUC6 & & & & & 244.0 & 266.0 & 1.0 & 1.0 \\
\hline \multirow[t]{2}{*}{ PAN3068 } & Paclitaxel $175 \mathrm{mg} / \mathrm{m}^{2}$ & 133 & 49 & 0.67 & 0.65 & 117.0 & 114.0 & 2.0 & 2.0 \\
\hline & Carboplatin AUC6 & & & & & 263.0 & 282.0 & 0.5 & 0.5 \\
\hline
\end{tabular}

${ }^{a}$ Administered in combination with bleomycin, dacarbazine and vinblastine.

Note: GA, gestational age; BSA, body surface area; Pr, pregnant; PP, postpartum; IT, infusion time; AUC, area under the curve. 
Table 2. Comparison of pharmacokinetic parameters of doxorubicin between pregnant and postpartum baboons.

\begin{tabular}{|c|c|c|c|c|c|c|c|c|c|c|}
\hline \multirow{2}{*}{$\frac{\text { Baboon: }}{\text { PK parameter }}$} & \multicolumn{3}{|c|}{ PAN2044 } & \multicolumn{3}{|c|}{ PAN2596 } & \multicolumn{3}{|c|}{ PAN3072 } & \multirow{2}{*}{$\begin{array}{l}\text { Mean } \\
\mathrm{Pr} / \mathrm{PP}\end{array}$} \\
\hline & $\operatorname{Pr}$ & PP & $\mathrm{Pr} / \mathrm{PP}$ & $\operatorname{Pr}$ & PP & $\mathrm{Pr} / \mathrm{PP}$ & $\operatorname{Pr}$ & PP & $\mathrm{Pr} / \mathrm{PP}$ & \\
\hline $\mathrm{C}_{\max }-\mathrm{D}(\mathrm{ng} / \mathrm{ml} / \mathrm{mg})$ & 56.3 & 94.5 & 0.60 & 87.4 & 152.3 & 0.57 & 87.2 & 131.4 & 0.66 & $0.61 \pm 0.05$ \\
\hline AUC - D (hour.ng/ml/mg) & 29.7 & 43.7 & 0.68 & 36.6 & 77.6 & 0.47 & 34.8 & 60.3 & 0.58 & $0.58 \pm 0.11$ \\
\hline $\mathrm{t}_{1 / 2}$ (hour) & 9.3 & 11.4 & 0.82 & 16.3 & 26.8 & 0.61 & 10.2 & 16.6 & 0.61 & $0.68 \pm 0.12$ \\
\hline Clearance (L/hour) & 33.7 & 22.9 & 1.47 & 27.3 & 12.9 & 2.12 & 28.7 & 16.6 & 1.73 & $1.77 \pm 0.33$ \\
\hline $\mathrm{V}_{\mathrm{d}}(\mathrm{L})$ & 449.9 & 375.7 & 1.20 & 640.3 & 499.2 & 1.28 & 421.0 & 399.9 & 1.05 & $1.18 \pm 0.12$ \\
\hline
\end{tabular}

Note: PK, pharmacokinetic; $\mathrm{C}_{\max }-\mathrm{D}$, the maximum concentration corrected for dose; AUC - D, area under the curve corrected for dose; $t_{1 / 2}$, terminal half-life; $V_{d}$, distribution volume.

and chemotherapy regimens are presented in Table 4 . Numbers of pregnant/nonpregnant patients treated were $5 / 2,7 / 5,4 / 4,2 / 2$ for paclitaxel, doxorubicin, epirubicin and carboplatin, respectively.

Intrapatient comparison of the most important pharmacokinetic parameters for doxorubicin, paclitaxel and carboplatin in patients receiving the same chemotherapy regimen during and after pregnancy $(n=3)$ is shown in Table 5. During pregnancy, an increased distribution volume and clearance were seen, resulting in a decreased AUC and $\mathrm{C}_{\max }$. For carboplatin and paclitaxel, the differences were less pronounced than for doxorubicin. In this patient the postpartum values were obtained 4 weeks after the delivery, which might be too short to exclude any impact of the pregnancy.

Table 6 shows the comparison of the pooled data of pregnant versus control patients for paclitaxel, carboplatin, doxorubicin and epirubicin. The data obtained show similar changes for all tested chemotherapeutic drugs. During pregnancy the distribution volume and clearance increased while the AUC $-\mathrm{D}$ and $\mathrm{C}_{\max }-\mathrm{D} \times \mathrm{IT}$ decreased.

\section{Discussion}

To the best of our knowledge, the impact of the pregnant state on the pharmacokinetics of cytotoxic drugs has not been studied in vivo in nonhuman primates or in humans yet. In a preclinical study in baboons, we tested the hypothesis that gestational alterations affect drug disposition resulting in a reduced plasma exposure to cytotoxic drugs after standard dosing. This finding was confirmed in a clinical study with analysis of intraindividual and pooled patient data. Therefore, it cannot be excluded that cytotoxic drug efficacy is also impaired during pregnancy. Overall, these data underscore the importance of long-term follow-up with regard to overall survival of women treated with chemotherapy during pregnancy.

To date, only one case report of paclitaxel pharmacokinetics during pregnancy has been reported, showing a decreased $\mathrm{C}_{\max }$ and AUC during pregnancy (10). This finding is confirmed in the current series.

As gestational changes in physiology are known to affect drug disposition in general, they can also alter exposure to chemotherapeutics (3). Consequently, these changes can result in subtherapeutic or toxic drug levels. Obviously, these situations should be prevented, particularly in oncology where patients are treated with potent, mutagenic and teratogenic chemotherapeutics.

The clinical impact of our findings may be considerable. Cytotoxic drugs during pregnancy are mostly administered for primary cancer treatment. In addition to surgery and/or radiotherapy, systemic cancer treatment adds to local and systemic tumor control.

Table 3. Comparison of pharmacokinetic parameters of paclitaxel and platinum between pregnant and postpartum baboons.

\begin{tabular}{|c|c|c|c|c|c|c|c|c|c|c|c|c|c|c|}
\hline \multirow{3}{*}{$\frac{\frac{\text { Drug }}{\text { Baboon }}}{\text { PK parameter }}$} & \multicolumn{7}{|c|}{ Paclitaxel } & \multicolumn{7}{|c|}{ Platinum } \\
\hline & \multicolumn{3}{|c|}{ PAN2656 } & \multicolumn{3}{|c|}{ PAN3068 } & \multirow{2}{*}{$\begin{array}{l}\text { Mean } \\
\mathrm{Pr} / \mathrm{PP}\end{array}$} & \multicolumn{3}{|c|}{ PAN2656 } & \multicolumn{3}{|c|}{ PAN3068 } & \multirow{2}{*}{$\begin{array}{l}\text { Mean } \\
\mathrm{Pr} / \mathrm{PP}\end{array}$} \\
\hline & $\operatorname{Pr}$ & PP & $\operatorname{Pr} / \mathrm{PP}$ & $\operatorname{Pr}$ & PP & $\mathrm{Pr} / \mathrm{PP}$ & & $\operatorname{Pr}$ & PP & $\mathrm{Pr} / \mathrm{PP}$ & $\operatorname{Pr}$ & PP & $\mathrm{Pr} / \mathrm{PP}$ & \\
\hline $\mathrm{C}_{\max }-\mathrm{D}(\mu \mathrm{g} / \mathrm{ml} / \mathrm{mg})$ & 73.1 & 271.0 & 0.27 & 126.9 & 184.7 & 0.69 & $0.48 \pm 0.30$ & & 82.0 & & 107.4 & 163.5 & 0.66 & 0.66 \\
\hline AUC - D (hour $\mu \mathrm{g} / \mathrm{ml})$ & 288.6 & 713.3 & 0.40 & 412.5 & 446.4 & 0.92 & $0.66 \pm 0.37$ & & 310.9 & & 316.2 & 434.5 & 0.73 & 0.73 \\
\hline $\mathrm{t}_{1 / 2}$ (hour) & 4.5 & 4.1 & 1.10 & 4.6 & 2.8 & 1.64 & $1.37 \pm 0.38$ & 51.9 & 40.8 & 1.27 & 13.7 & 7.8 & 1.76 & $1.52 \pm 0.35$ \\
\hline Clearance (L/hour) & 3.5 & 1.4 & 2.50 & 2.4 & 2.2 & 1.09 & $1.80 \pm 1.00$ & 4.2 & 3.2 & 1.31 & 3.2 & 2.3 & 1.39 & $1.35 \pm 0.06$ \\
\hline $\mathrm{V}_{\mathrm{d}}(\mathrm{L})$ & 22.7 & 8.3 & 2.73 & 16.1 & 9.1 & 1.77 & $2.25 \pm 0.68$ & 311.2 & 189.5 & 1.64 & 62.6 & 26.0 & 2.41 & $2.03 \pm 0.54$ \\
\hline
\end{tabular}

Note: PK, pharmacokinetic; $\mathrm{C}_{\max }-\mathrm{D}$, the maximum concentration corrected for dose; AUC $-\mathrm{D}$, area under the curve corrected for dose; $\mathrm{t}_{1 / 2}$, terminal half-life; $\mathrm{V}_{\mathrm{d}}$, distribution volume. 
Table 4. Patient characteristics, chemotherapy and dosing schedule.

\begin{tabular}{|c|c|c|c|c|c|c|c|c|}
\hline $\mathrm{Pt}$ & $\begin{array}{c}\text { Age } \\
\text { (year) }\end{array}$ & Malignancy & $\begin{array}{c}\text { GA } \\
\text { (week) }\end{array}$ & $\begin{array}{l}\text { Control } \\
\text { samples }\end{array}$ & $\begin{array}{l}\text { BSA } \\
\left(\mathrm{m}^{2}\right)\end{array}$ & Chemotherapy & Tested drug & $\begin{array}{c}\text { Dosage } \\
\left(\mathrm{mg} / \mathrm{m}^{2}\right)\end{array}$ \\
\hline \multirow[t]{2}{*}{1} & 32 & Breast & 31 & & 2.14 & FAC & Doxorubicin & 65 \\
\hline & & & & $61 \mathrm{~d} P P$ & 2.05 & TAC & Doxorubicin & 50 \\
\hline 2 & 34 & Breast & 31 & & 1.80 & FAC & Doxorubicin & 60 \\
\hline \multirow[t]{2}{*}{3} & 32 & Breast & 31 & & 2.00 & $\mathrm{AC}$ & Doxorubicin & 60 \\
\hline & & & & 49 d PP & 1.87 & $\mathrm{AC}$ & Doxorubicin & 60 \\
\hline \multirow[t]{2}{*}{4} & 26 & Breast & 29 & & 1.78 & FAC & Doxorubicin & 50 \\
\hline & & & 31 & & 1.79 & Paclitaxel & Paclitaxel & 175 \\
\hline 5 & 34 & Breast & 32 & & 1.83 & $\mathrm{AC}$ & Doxorubicin & 60 \\
\hline 6 & 34 & Breast & 32 & & 1.74 & $\mathrm{AC}$ & Doxorubicin & 60 \\
\hline 7 & 17 & Hodgkin & & NP & 1.71 & ABVD & Doxorubicin & 25 \\
\hline 8 & 54 & Hodgkin & & $\mathrm{NP}$ & 1.68 & ABVD & Doxorubicin & 25 \\
\hline \multirow[t]{2}{*}{9} & 32 & NHL & 22 & & 1.65 & CHOP & Doxorubicin & 50 \\
\hline & & & & $44 \mathrm{~d}$ PP & 1.70 & R-CHOP & Doxorubicin & 50 \\
\hline 10 & 40 & Breast & 31 & & 1.92 & FEC & Epirubicin & 100 \\
\hline 11 & 33 & Breast & 30 & & 2.33 & FEC & Epirubicin & 75 \\
\hline 12 & 36 & Breast & 19 & & 1.85 & FEC & Epirubicin & 100 \\
\hline 13 & 36 & Breast & 32 & & 1.88 & FEC & Epirubicin & 100 \\
\hline 14 & 48 & Breast & & $\mathrm{NP}$ & 1.53 & FEC & Epirubicin & 100 \\
\hline 15 & 35 & Breast & & $\mathrm{NP}$ & 1.70 & FEC & Epirubicin & 100 \\
\hline 16 & 31 & Breast & & NP & 1.66 & FEC & Epirubicin & 100 \\
\hline 17 & 31 & Breast & & $\mathrm{NP}$ & 1.59 & FEC & Epirubicin & 100 \\
\hline 18 & 36 & Ovarian & 29 & & 1.75 & Paclitaxel-Cisplatin & Paclitaxel & 175 \\
\hline \multirow[t]{2}{*}{19} & 34 & Ovarian & & NP & 1.66 & Paclitaxel-Carboplatin & Paclitaxel & 175 \\
\hline & & & & & & & Carboplatin & AUC6 \\
\hline 20 & 36 & Ovarian & 23 & & 1.93 & Paclitaxel & Paclitaxel & 175 \\
\hline \multirow[t]{4}{*}{21} & 28 & Ovarian & 23 & & 1.77 & Paclitaxel-Carboplatin & Paclitaxel & 175 \\
\hline & & & & & & & Carboplatin & AUC5 \\
\hline & & & & $30 \mathrm{~d} P P$ & 1.83 & Paclitaxel-Carboplatin & Paclitaxel & 175 \\
\hline & & & & & & & Carboplatin & AUC5 \\
\hline \multirow[t]{2}{*}{22} & 34 & Cervical & 25 & & 1.93 & Paclitaxel-Carboplatin & Paclitaxel & 175 \\
\hline & & & & & & & Carboplatin & AUC5 \\
\hline
\end{tabular}

Note: GA, gestational age; d, days; PP, postpartum; NP, nonpregnant; NHL, non-Hodgkin lymphoma; ABVD, Doxorubicin, Bleomycin, Vinblastine, Dacarbazine; (F)AC, (5-Fluorouracil), Doxorubicin, Cyclophosphamide; FEC, 5-Fluorouracil, Epirubicin, Cyclophosphamide; (R-)CHOP, (Rituximab), Cyclophosphamide, Doxorubicin, Vincristine, Prednisolone.

Table 5. Intraindividual comparison of the most important pharmacokinetic parameters of doxorubicin, paclitaxel and carboplatin during pregnancy and postpartum.

\begin{tabular}{|c|c|c|c|c|c|c|c|c|c|}
\hline Drug & $\mathrm{Pt}$ & & $\begin{array}{l}\text { Time } \\
\text { (week) }\end{array}$ & $\begin{array}{l}\text { BSA } \\
\left(\mathrm{m}^{2}\right)\end{array}$ & $\begin{array}{c}\mathrm{t}_{1 / 2} \\
\text { (hour) }\end{array}$ & $\begin{array}{l}\mathrm{C}_{\max }-\mathrm{D} \times \mathrm{IT} \\
(\mathrm{ng} / \mathrm{ml} \cdot \mathrm{mg} \cdot \text { hour })\end{array}$ & $\mathrm{V}_{\mathrm{d}}(\mathrm{L})$ & $\begin{array}{l}\text { Clearance } \\
\text { (L/hour) }\end{array}$ & $\begin{array}{c}\text { AUC - D } \\
\text { (hour.ng/ml/mg) }\end{array}$ \\
\hline \multirow[t]{6}{*}{ Doxorubicin } & \multirow[t]{3}{*}{3} & $\operatorname{Pr}$ & 31 & 2.00 & 32.41 & 7.47 & $3,066.68$ & 65.59 & 15.25 \\
\hline & & PP & 7 & 1.87 & 33.05 & 9.85 & $1,574.92$ & 33.03 & 30.28 \\
\hline & & $\mathrm{Pr} / \mathrm{PP}$ & & 1.07 & 0.98 & 0.76 & 1.95 & 1.99 & 0.50 \\
\hline & \multirow[t]{3}{*}{9} & $\operatorname{Pr}$ & 22 & 1.65 & 20.99 & a & $2,356.43$ & 77.82 & 12.85 \\
\hline & & PP & 6.5 & 1.70 & 25.83 & 10.15 & $1,813.23$ & 48.66 & 20.55 \\
\hline & & $\mathrm{Pr} / \mathrm{PP}$ & & 0.97 & 0.81 & & 1.30 & 1.60 & 0.63 \\
\hline \multirow[t]{3}{*}{ Paclitaxel } & \multirow[t]{3}{*}{21} & $\operatorname{Pr}$ & 23 & 1.77 & 9.41 & 32.09 & 391.94 & 28.86 & 34.65 \\
\hline & & PP & 4 & 1.83 & 13.92 & 38.20 & 537.57 & 26.77 & 37.36 \\
\hline & & $\mathrm{Pr} / \mathrm{PP}$ & & 0.96 & 0.68 & 0.84 & 0.73 & 1.08 & 0.93 \\
\hline \multirow[t]{3}{*}{ Carboplatin } & \multirow[t]{3}{*}{21} & $\operatorname{Pr}$ & 23 & 1.77 & 29.84 & 10.64 & 432.81 & $10,053.04$ & 99.47 \\
\hline & & PP & 4 & 1.83 & 21.91 & 10.68 & 271.83 & $8,600.11$ & 116.28 \\
\hline & & $\mathrm{Pr} / \mathrm{PP}$ & & 0.96 & 1.36 & 1.00 & 1.59 & 1.17 & 0.86 \\
\hline
\end{tabular}

${ }^{a}$ Sample was not collected exactly at the end of the infusion, and therefore $\mathrm{C}_{\max }$ is considered unreliable.

Note: Pr, pregnant; PP, postpartum; BSA, body surface area; IT, infusion time; $\mathrm{C}_{\max }-\mathrm{D} \times \mathrm{IT}$, maximal concentration corrected for dose and infusion time; $\mathrm{V}_{\mathrm{d}}$, distribution volume; AUC - D, area under the curve corrected for dose. 
The observed alterations in systemic exposure to chemotherapeutic drugs during pregnancy may reduce therapeutic efficacy. Currently, there are no indications suggesting that patients with cancer when treated during pregnancy with standard height-weight based dosed chemotherapy are at higher risk of reduced efficacy or more toxicity compared to nonpregnant patients $(11,12)$. However, the conclusion that the prognosis is not worse for pregnant women deserves a critical note. In the available studies, the number of patients per tumor type does not allow controlling for the assessed treatment and specific prognostic markers. Moreover, the reported results are based on a relative short follow-up period $(11,12)$. Our study indicates that the subgroup necessitating chemotherapy deserves special attention. Although the existing data are reassuring, only larger series with sufficient follow-up can determine the impact of pregnancy on maternal outcome.

Two pharmacokinetic aspects can be the reason why pregnancy might not necessarily worsen the prognosis when chemotherapy is administered in a standard dose. Firstly, the tissue effect is determined by the unbound/free drug fraction, and this fraction is susceptible to gestational changes. Chemotherapeutic agents are highly protein-bound (paclitaxel $>95 \%$, anthracyclines $50-85 \%$, carboplatin $24-50 \%$ ) (13). Gestational dilutional hypoalbuminemia may result in a higher unbound drug fraction (3). We attempted to measure the free drug fraction of doxorubicin, epirubicin and paclitaxel. However, the unbound fraction was below the lower limit of quantification in most samples at the time of steady state drug concentrations. Moreover, since relatively small alterations in free drug concentration can be expected, a large series of patients is required to overcome the normal interindividual variability. In the current series, only in patient 1 could an intraindividual comparative result of the free doxorubicin concentration be obtained 2 hours after exposure. The gestational and postpartum free drug fraction was 25 and $10 \%$, respectively. This finding indicates that future research should incorporate free drug measurements.

Secondly, some drugs show a preferential binding to tumor tissue (14). Koshiba and colleagues compared tissue concentrations of paclitaxel and carboplatin in tumoral and non-tumoral cervical, endometrial and ovarian tissue. They measured higher paclitaxel concentrations in tumor tissue than in normal tissue. For carboplatin no difference was seen. This difference could probably be explained by the binding site of the paclitaxel, $\beta$-tubulin (vs. DNA for carboplatin), which might have a higher 
expression in fast-dividing tumoral cells. Moreover, the tumor concentration of paclitaxel could be linked to progression free survival (14). Therefore, measurements of tumoral drug concentrations are preferably incorporated in future studies.

Given the rarity of cancer during pregnancy, it is not feasible in the short term to achieve conclusive data on maternal outcome after chemotherapy during pregnancy - corrected for the different diseaserelated prognostic factors. Currently available surrogate markers for tumor toxicity such as bone marrow toxicity, quantification of side effects (e.g. hair loss, nausea, neutropenic fever) or biomarkers for toxicity or tumor activity, are either unreliable or still in an early experimental phase of development $(13,15)$.

A limitation of the present report is the small number of baboons and patients, which does not allow to achieve statistically significant data. However, the tendency of findings is consistent for all tested drugs. We continue to motivate both pregnant and nonpregnant women to participate in our studies in order to increase numbers.

To conclude, these data support the hypothesis that the physiologic changes of pregnancy alter the disposition of chemotherapeutic agents resulting in a decreased plasma drug exposure of standarddosed chemotherapy. Further research is warranted to translate the differences in plasma levels into alterations in tumor concentration and treatment efficacy. The importance of long-term follow-up with regard to overall survival of women treated with chemotherapy during pregnancy is underscored.

In addition, these data support continued research focusing on the free drug fraction, tissue drug concentrations and the maternal outcome.

\section{Acknowledgments}

We are very grateful to Gunther Guetens and Sonia Demarsin for their assistance in the analyses. This research is supported by Research FoundationFlanders (F.W.O.) [Project G. 0358.06], 'Stichting tegen kanker [Project SCIE2006-17], Research Fund-K.U.Leuven [OT/07/053], Clinical Research Fund University Hospital Gasthuisberg and Nationaal kankerplan [FOD NKP 29 038]. FA is clinical researcher for Research FoundationFlanders (F.W.O.); KVC is aspirant for Research Foundation-Flanders (F.W.O.).
Declaration of interest: The authors report no conflicts of interest. The authors alone are responsible for the content and writing of the paper.

\section{References}

1. Undevia SD, Gomez-Abuin G, Ratain MJ. Pharmacokinetic variability of anticancer agents. Nat Rev Cancer. 2005;5: 447-58

2. Krauer B, Krauer F, Hytten FE. Drug disposition and pharmacokinetics in the maternal-placental-fetal unit. Pharmacol Ther. 1980;10:301-28.

3. Koren G (ed). Maternal-fetal toxicology. A clinician's guide. New York: Marcel Dekker Inc., 2001.

4. Wiebe VJ, Sipila PE. Pharmacology of antineoplastic agents in pregnancy. Crit Rev Oncol Hematol. 1994;16: 75-112.

5. Cardonick E, Iacobucci A. Use of chemotherapy during human pregnancy. Lancet Oncol. 2004;5:283-91.

6. Garland M, Szeto HH, Daniel SS, Tropper PJ, Myers MM, Stark RI. Zidovudine kinetics in the pregnant baboon. J Acquir Immune Defic Syndr Hum Retrovirol. 1996;11: 117-27.

7. Hendrickx AG, Kraemer DC. Reproduction. In: Hendrickx AG (ed). Embryology of the baboon. Chicago: University of Chicago Press, 1971. pp. 22-50.

8. Calvert AH, Newell DR, Gumbrell LA, O'Reilly S, Burnell M, Boxall FE, et al. Carboplatin dosage: prospective evaluation of a simple formula based on renal function. J Clin Oncol. 1989;7:1748-56.

9. Quadri KH, Bernardini J, Greenberg A, Laifer S, Syed A, Holley JL. Assessment of renal function during pregnancy using a random urine protein to creatinine ratio and Cockcroft-Gault formula. Am J Kidney Dis. 1994;24:416-20.

10. Lycette JL, Dul CL, Munar M, Belle D, Chui SY, Koop DR, et al. Effect of pregnancy on the pharmacokinetics of paclitaxel: a case report. Clin Breast Cancer. 2006;7: 342-4.

11. Stensheim H, Moller B, van Dijk T, Fossa SD. Cause-specific survival for women diagnosed with cancer during pregnancy or lactation: a registry-based cohort study. J Clin Oncol. 2009; 27:45-51

12. Cardonick E, Dougherty R, Grana G, Gilmandyar D, Ghaffar S, Usmani A. Breast cancer during pregnancy: maternal and fetal outcomes. Cancer J. 2010;16:76-82.

13. De Vita VJ, Hellman S, Rosenberg S. Cancer principles and practice of oncology. Philadelphia: Lippincott Williams \& Wilkins, 2001.

14. Koshiba H, Hosokawa K, Mori T, Kubo A, Watanabe A, Honjo H. Intravenous paclitaxel is specifically retained in human gynecologic carcinoma tissues in vivo. Int J Gynecol Cancer. 2009;19:484-8.

15. Rockett JC, Burczynski ME, Fornace AJ, Herrmann PC, Krawetz SA, Dix DJ. Surrogate tissue analysis: monitoring toxicant exposure and health status of inaccessible tissues through the analysis of accessible tissues and cells. Toxicol Appl Pharmacol. 2004;194:189-99. 